\title{
Analyzing The Effects Of Product Label Messages On Consumers' Attitudes And Intentions
}

Ifrim Mihaela-Roxana

Yoon C. Cho, Ph.D., KDI School of Public Policy and Management, Korea

\begin{abstract}
Customer attitudes toward products are affected by both cognitive and emotional constructs to different degrees. The purpose of this study is to investigate how customers' perception of the content of product labels affects the attitudes toward the product and the labels' intentions. In particular, this study considers how the cognitive and emotional aspects of awareness levels of message contents impact overall attitudes toward sugar-free beverages. This study explores how such impacts are balanced by the consideration of double-edged health-related concerns. By divining customers' perceptions of the products, the study examines i) the effects of cognitive and emotional constructs to the overall attitudes and; ii) the effects of cognitive and emotional constructs to the conative factor. Surveys were conducted and statistical analyses, such as factor, regression, and ANOVA, were applied to investigate the findings. Furthermore, this study examines the implications of managerial and theoretical applications and offers suggestions for businesses.
\end{abstract}

Keywords: Message Contents, Product Labels, Awareness, Attitudes, and Behavior.

\section{INTRODUCTION}

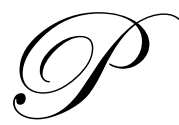

revious studies have suggested that the information labelled on products can potentially affect decision making, product quality, and price [Bettman, Payne, \& Staelin 1986 (Mazis, Staelin, Beales, \& Salop 1981)]. Product information might lead customers to make the right decisions, although customers often pass over the information due to such reasons as low attention levels and a lack of knowledge about the ingredients. How the message is elucidated and conveyed to customers also depends on various issues such as how the contents of messages are developed. Muller (1985), for instance, questioned whether customers actually use the information noted on their products, in particular regarding foods.

Amidst the information included on products, how "warning" messages affect attitude changes or decision making has been investigated by various studies. A study by Stewart and Martin (1994), observed that warnings can be distinguished from other types of labels by their function. Stewart and Martin (1994) stated that perceived warnings are stimuli that alert people to hazardous conditions with the human factor's perspective, while the effectiveness of warnings varied based on the perceived level of target audience. The authors also stated that a specific target audience is identified in some warnings, whereas others are directed at an unidentified or general audience. A study by Mayer, Smith, and Scammon (1991) also noted that warnings, an appealing policy tool frequently used by policy makers, have limited evidence of effectiveness in terms of altering individual behaviour. Stewart and Martin (1994) argued that exposure and attention to warnings do not ensure that the warnings are perceived as credible, nor do they provide insight into whether and under what circumstances consumers will alter their attitudes, decision making, or behaviors in response to the warnings.

Previous studies have suggested that the information content of warnings can differ in a variety of dimensions, such as various forms, criteria, and the purposes of warning messages (Stewart \& Martin 1994) that are 
shared by the many characteristics of labels (Brown, Kelly, \& Lee 1991; Miller 1978). Torres, Sierra, and Heiser (2007) have argued that warning information is conveyed for many reasons, one of which is altruism (i.e., to inform consumers and help generate a safe consumer response toward a product). If consumers fail to detect a warning, it is obviously communicated ineffectively (Hilton 1993; Torres, Sierra, \& Heiser 2003). The warning policies that have been most extensively researched concern cigarettes and alcohol (Mayer, Smith, \& Scammon 1991) and foods that are related to the weight control. Stewart and Martin (1994) also found that among commercial products that carry warning messages, alcoholic beverages, cigarettes and other tobacco products, saccharin, and over-the-counter (OTC) medications (especially aspirin for children) are among the more controversial.

With the above considerations, the purpose of this study is to measure how customers' attitudes on sugarfree products which contain various artificial ingredients are affected by the warning messages of the product labels. This study posits that the effectiveness of warning information depends upon how customers comprehend the congruity between the contents of the warning information and the tendency to heed the warnings as relating to them. In particular, this study explores customers' willingness to consume the products and their overall attitudes along with message contents on sugar-free products. Sugar-free products are selected for this study in order to determine how customers perceive the benefits of the products (e.g., losing weight) and the risks (e.g., taking artificial ingredients) and how there considerations affect their decision making. Therefore, the purpose of this study is to explore i) how cognitive factors elicited by sugar-free beverages affect overall attitudes toward the products and the intention to purchase a product; and ii) how emotional factors elicited by the sugar-free beverages affect overall attitudes toward the products and the intention to purchase a product. By investigating cognitive factors, this study measures the impacts of self-congruity, normative beliefs, and perceived awareness to attitudes and intention.

\section{LITERATURE REVIEW}

A study by Bettman, Payne, and Staelin (1986) addressed the limitation of human processing due to people's abilities to make rational decisions about risks and benefits. Previous studies have indicated that people would find "rational decisions" difficult to trade off "costs and benefits" against "the greater perceived benefits and also with greater perceived risk" (Johnson and Payne 1985; Payne, Bettman, \& Johnson1993). This study posits that the perception of food safety which is cultural and personal has also been followed by rational decision making. Among the products included in food safety, sugar is perceived in general as being unhealthy, while sweeteners are commonly seen as alternatives with fewer calories, though artificially made (Meyer, 2008). However, consumers' trust in the healthfulness of sweeteners is accompanied by a moral hazard (Meyer, 2008). Customers, in general, have long developed a healthy diet, consisting of many vegetables and traditional herbal drinks, and a health craze erupted (Meyer, 2008) leading many consumers to search for "well-being" foods and beverages. The choice of products is often determined by many factors, such as thirst-quenching attributes, taste, nutritional value, packaging, advertising, word-of-mouth, social pressure and group influences, health benefits, emotional benefits, fear of disease, and many others (Meyer, 2008). These factors mix in various proportions in different individuals and influence their intentions to choose a certain beverage (Meyer, 2008).

This research was conducted to investigate the attitudes towards sugar-free beverages and the way they are linked to the purchasing behavior by means of understanding the customer. What motives a customer to purchase sugar-free beverages is affected by whether or not the customer is aware of potential hazards and/or the decision triggers the processing of additional information in the memory (Stewart \& Martin 1994). Motivations to choose sugar-free beverages could be also explained by several actors pursing issues of interest, including consumers, marketers, and the government regulation by weighing health. Numerous researchers (e.g. Rotter 1954, Ajzen \& Fishbein 1980, Bandura 1977, 1982, Bagozzi 1978) have attempted to develop models that can explain consumers' mechanisms for making a certain choice of product. Broadly, researchers (e.g., Ajzen \& Fishbein 1980) have followed three perspectives on consumer behavior: decision-making, experiential and behavioral models. This study posits that product importance and hedonic involvement contribute in different proportions to the ways consumers recognize their needs and search for suitable products based on factors such as personality, personal values, lifestyle, knowledge, attitudes and beliefs (Kotler \& Armstrong 2009). Such factors also influence all stages of the buying decision process: need recognition, information search, evaluation of alternatives, purchase decision and postpurchase behavior (Kotler \& Armstrong 2009). In the case of sugar-free beverages and other functional drinks, consumers often put in more effort to purchase their favorite drink, as they are looking for specific benefits without 
even passing over the warning messages. Consumers often spend physical effort (e.g., product comparison) and mental effort (e.g., warning messages) to decide among brands or product types available in order to purchase sugarfree beverages. Knowledgeable consumers may pay attention to the ingredients used for a certain drink and make their choice based on these details (Bucklin 1963). The sugar-free drinks are therefore higher in risk than the regular ones and consumers may want to minimize their risk by learning about the product they intend to purchase. Soft drinks in general are low-intensity products (Bucklin 1963) and are purchased with low involvement from the buyer. However, in the case of sugar-free beverages, we may find consumers in a higher degree of involvement, since many heavy dieters are very careful to avoid sugary beverages. These facts suggest the search for information should be more extensive in the case of diet drinks.

\subsection{Theoretical foundations}

This study investigates factors involved in most consumers' intention to consume a type of functional drinks (i.e., sugar free beverages) that contain artificial ingredients. This study investigates what type of benefits consumers expect from their sugar-free drinks and how much these beverages affect their expectations. In this paper, authors examine how cognitive (e.g., perceived awareness) and emotional (e.g., fear of gaining weight) factors affect overall attitudes and intentions toward sugar-free drinks. This study attempts to measure consumers' attitudes and beliefs towards sugar-free beverages by applying previous theories and models. The proposed model incorporates both cognitive and emotional factors, and broadens the Theory of Reasoned Action (Ajzen\& Fishbein 1980) by adding the perceived awareness, self-concept congruity, and normative belief as cognitive variables, and noncognitive variables such as emotional feeling. Emotional feelings such as hedonic involvement (Fitzmaurice 2005) and fear of disease have been addressed from the Health Belief Model (Glanz \& Lewis 2002). Since consumers are not always fully aware of their motivations for making a certain purchase, this research aims to investigate deeper into each individual's mind in search of possible hidden reasons.

The proposed model is explained by the tri-component (Schiffman \& Kanuk, 2003; Rosenberg and Hoveland 1960) view of attitudes. While the tri-component model considered effects of cognitive and affective factors to the behavioral intention, this study investigates effects of those variables to the overall attitudes. The model also considered Hierarchy of Effects (Krugman and Hartley 1970) with respect to the idea that attitudes precede behavior in the buying decision process for sugar-free beverages. Although the model borrows elements from value-expectancy model (Ajzen and Fihbein 1980), it essentially differs from TRA which suggested that attitudes affect intentions, which then lead to behavior. The model attempts to incorporate beliefs about the utilitarian benefits, typically explored in multi-attribute models- and beliefs about the symbolic or value-expressive functions (Sirgy 1986, Johar and Sirgy 1991) of sugar-free beverages, common in congruity theories.

The psychoanalytical theory (Blackwell, Miniard, Engel, 2006) has demonstrated that the human behavior is often poorly explained by what people think they know. According to Freud (1953) who revolutionized our perception of the human mind from the iceberg theory, "we are effectively cognitive icebergs with most of our thoughts occurring below the water line." According to Freud's theory (1953), the conscious part of our mind is like the top of the iceberg; in other words, what we can know and understand logically is just around $10 \%$ of our mind; the largest part of the iceberg is under the water and consists of the preconscious (subconscious) and the unconscious mind. As suggested by Freud (1953), although we may think we make our decisions based on the information we are consciously aware of, or we can easily retrieve from memory (the subconscious level), our behavior is in fact determined by things we are not aware of, and are stored in our unconscious. Therefore, why sometimes consumers buy products without knowing why they purchased it is explained by the theory (Freud 1953). A different approach to explaining human behavior was initiated by social psychology; unlike Freud's psychoanalytic theory which emphasized the importance of biological instincts, the social psychological theory considered social variables to be stronger motivators of behavior (Blackwell, Miniard, Engel, 2006).

As indicated by Maslow (1954), people are "self-actualizing" themselves, in other words they are making intelligent choices to improve and reach superior levels. However, the importance given to the different classes of needs at a particular time varies from one individual to another (Maslow 1954). In this respect, a consumer would choose a sugar-free drink to satisfy his thirst, while another one may do it because his behavior boosts his selfesteem, or because he anticipates that by doing so, he can be admired by other people. A hierarchy of needs with 
physiological needs at the bottom, followed by the needs for safety and security, the needs for love and belonging, the needs for esteem, and on top of the pyramid, the need to actualize the self (Maslow 1954). The road opened by Maslow (1954) was continued by researchers investigating personal values. Values that are stated by Gutman (1982)'s the Means-End theory, are considered to play an important role in the first stages of the buying decision, when consumers recognize that they have a particular need (Gutman 1982). Kahle (1983) suggested that values are formed from individuals' personal experiences and learning situations and they are guiding the human behavior. Therefore attitudes are derived from values, and together influence the intention to perform a behavior (Kahle, 1983). The approach by Gutman (1982) aims at discovering the linkages between product attributes (the "means"), the consequences for the consumer provided by the attributes (or the perceived benefits), and personal values (the "ends"). The means-end perspective, similar with the Expectancy-Value Theory introduced by Rosenberg (1956), explains how consumer actions produce consequences and how consumers learn to associate particular outcomes with specific product attributes. In other words, consumers learn to choose products containing attributes which are instrumental to achieving their desired consequences Rosenberg (1956).

\section{HYPOTHESES DEVELOPMENT}

The model (Figure 1) proposed in this study includes cognitive and affective variables, overall attitudes and conative variables. While researchers have often considered intention as a mediator between the overall attitudes and satisfaction, this study measured separate effects of cognitive and emotional factors to overall attitudes and the willingness to purchase a product. The "cognitive variables" refer to subjective judgments and beliefs (Ajzen \& Fishbein 1980) about sugar-free beverages, in terms of what they do, as functional products, and in respect to what they mean to consumers, as value-expressive products; here are included the perceived awareness, beliefs about the functional congruity between product attributes and the expected benefits, beliefs about the normative beliefs, and beliefs based on perceived awareness level about the congruity of self-concept/product image (Ajzen \& Fishbein 1980; Solomon 2008). The "emotional variables" considered fear of gaining weight, enjoyment and eagerness to drink sugar-free beverages (Ajzen \& Fishbein 1980; Solomon 2008).

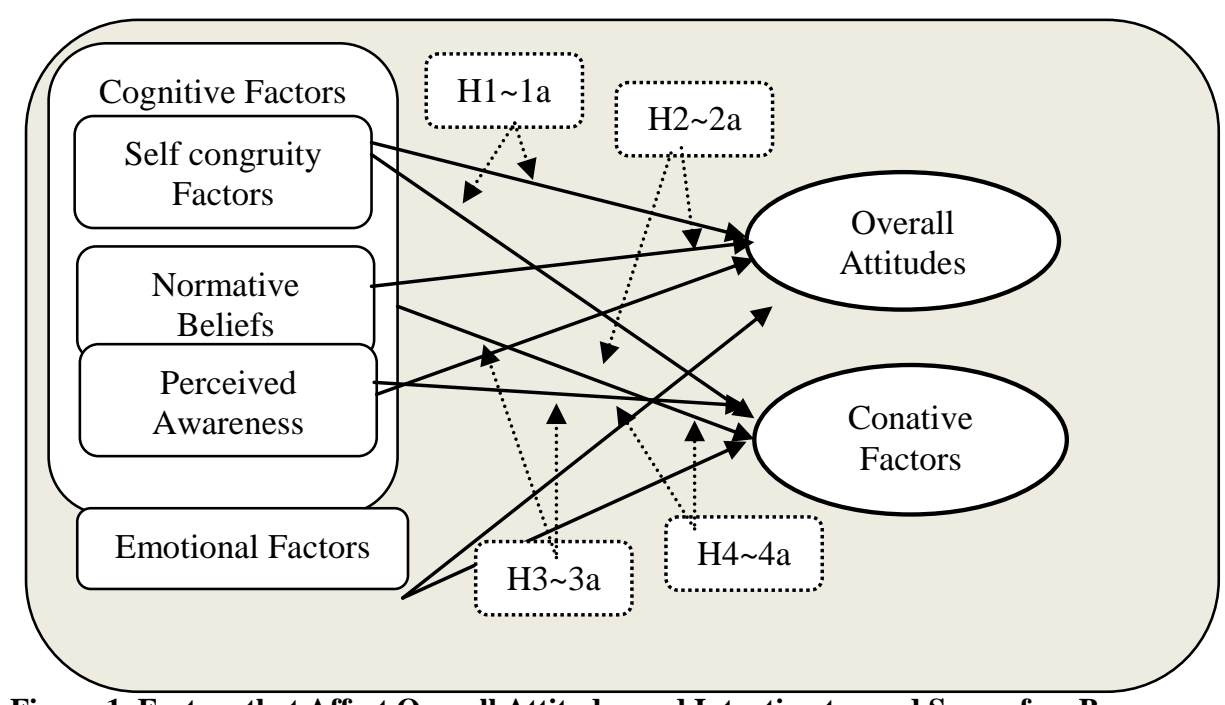

Figure 1. Factors that Affect Overall Attitudes and Intention toward Sugar-free Beverages

\section{Cognitive Factors}

Cognitive factors have long been found to be major components of attitudes (Solomon 2008). This model incorporates the following cognitive variables. Self-concept congruity, which refers to consumers' beliefs about how much sugar-free drinks match their self-image also considered as cognitive factor. Grubb and Gratwhol (1967) posit that consumers will direct their funds "toward furthering and enhancing self-concept throughout the consumption of 
goods as symbols." The concept of self-congruity is used in the context of symbolic consumption and is explained that consumers use product symbolism to define themselves (Sirgy 1986). Self-concept congruity differs from the functional congruity previously as the latter refers to the match between product's attributes or utilitarian aspects and consumers expectations regarding product performance (Sirgy 1986; Grubb and Gratwhol 1967). As different consumers look for different types of benefits from sugar-free beverages, self-concept congruity is expected to be a predictor of intention for those consumers seeking emotional benefits, being less important for those who drink sugar-free beverages motivated by their functional attributes. Sirgy's congruity theory suggests that the more consumers identify with the personality of sugar-free drinks or with the image of their typical consumer "the healthconscious," the higher is their motivation to consume them. The self-concept theory (Sirgy 1986, Wright, Clairbone, \& Sirgy 1992) also suggests that consumers may form or even change their self perception as a result of using a product. Therefore, consumers who drink sugar-free beverages may think that they can infuse themselves with the products' image, which in turn can boost their self-confidence and make them feel better about themselves. Furthermore, consumers are more likely to appreciate sugar-free drinks as value-expressive products, which can communicate meaning about the user to others. A higher congruity of self-concept/image of sugar-free drinks is expected to lead to stronger intentions, and more positive attitudes.

This study considered effects of normative beliefs, which take the form of perceived social pressure (Ajzen and Fishbein 1980). Normative beliefs taking the form of perceived social pressure may also weight significantly (Ajzen and Fishbein 1980), due to reasons; i) how a customer keep in a healthy condition by losing weights; or ii) how a customer perceives his or her health by perceiving warning messages. Subjective norm, another cognitive factor, refers to consumers' perception of whether their friends, family and colleagues approve of their behavior (Ajzen and Fishbein 1980). It can be expressed as beliefs about other people's opinions with respect to sugar-free beverages. According to Ajzen and Fishbein (1980), the more individuals perceive that their significant others think they should perform the behavior, the more they will be willing to do so. The perceived favorable or unfavorable opinions are weighted by the motivation consumers have to comply with them, and the sum of all these weighted perceptions represents the overall subjective norm. Individuals confer different weights to different opinions, depending, among others, on cultural influences, personality, sex or age (Ajzen and Fishbein 1980).

Among cognitive variables, perceived awareness, as a subjective self-assessment of consumers' knowledge, has been a measure of how much consumers believe they know about sugar-free beverages and it is proposed as influencing the overall attitudes via intention. Little (2002) viewed attitudes as "accumulation of information about an object", a predisposition to act in a positive or negative manner towards the object. Functional congruity, based on the utilitarian criteria such as belief-evaluation or belief-importance has been confirmed as a strong predictor of intention (Earl \& Kemp, 1999) in multi-attribute research. In this study it refers to the perceived weight management benefits or perceived health benefits associated with the functional attributes of sugar-free beverages. Consumers who associate sugar-free drinks with higher levels of functional benefits, such as weight control or health improvement are expected to have stronger intentions and more positive attitudes. Therefore, it is hypothesized that higher perceived level of cognitive factors affect increased attitudes and intention to consume sugar-free beverages.

H1: Higher degrees of self-concept congruity affect positive attitudes toward sugar-free beverages.

H1a: Higher degrees of self-concept congruity factors affect increased intention to purchase sugar-free beverages.

H2: Higher degrees of normative beliefs affect positive attitudes toward sugar-free beverages.

H2a: Higher levels of normative beliefs affect increased intention to purchase sugar-free beverages.

H3: Higher levels of perceived awareness affect positive attitudes toward sugar-free beverages.

H3a: Higher levels of perceived awareness affect increased intention to purchase sugar-free beverages.

\section{Emotional Factors}

Affect has often been seen as an essential component of attitudes. For the affective variables, concepts along with fear of gaining weight, fear of sweeteners, enjoyment (hedonic involvement) and eagerness were considered in prior studies. Among the concepts, fear is considered in two different forms: fear of gaining weight, proposed as a motivator (Witte, 1998) of intention and fear of sweeteners, the ingredients used to sweeten sugar-free drinks, proposed as an inhibitor (Witte, 1998). Fear has been conceptualized as "a negatively-valenced emotion, accompanied by a high level of arousal (Witte, 1998) and elicited by a threat that is perceived to be significant and 
personally relevant" (Easterling \& Leventhal 1989; Lang 1984; Ortony \& Turner 1990, Witte 1992). In the case that fear of gaining weight is related to the negative reinforcement, often used in fear advertising appeals. Consumers learn to believe that regular drinks with sugar may cause gaining weight. Therefore there is a need to take sugar-free beverages if they want to keep their shape. Previous studies (Rogers 1975, Witte 1992) also stated that fear can play an essential role in the formation of attitudes, and fear appeals may be a source of attitude change. Another implication of fear as an inhibitor includes the risk consumers may perceive from drinking beverages containing sweeteners. Many people do not fully understand effects of chemical substances even though they may have heard of health risks associated with sweetener consumption. The more afraid consumers are, the less strong intention they will have, and their attitudes towards sugar-free drinks will be less favorable.

This study measures the effects of emotional feelings to the attitudes and intention to the sugar-free beverages. The degree of enjoyment or pleasure associated by consumers with (drinking) sugar free beverages is expected to impact to the positive attitudes. Consumers are expected to be more willing to drink sugar-free beverages if they enjoy the taste and do not have to worry about calories. Fitzmaurice (2005) stated that the "arousal potential" of hedonic involvement, explaining that people will be more likely to perform a behavior that is anticipated as a source of pleasure and enjoyment. Eagerness, as explained by Fitzmaurice (2005) refers to goal oriented emotions, or "a desire to move forward." In the case of sugar-free beverages, a strong desire can take the form of cravings or compulsive consumption when consumers want to drink more and more of the product. Eagerness is thought to impact consumers' attitudes indirectly, through their intention. Therefore, it is hypothesized that consumers' higher degree of emotional feeling will affect increased attitudes and intention toward sugar-free beverages.

H4: Higher degrees of emotional factors affect positive attitudes toward sugar-free beverages.

H4a: Higher levels of emotional factors affect increased intention to purchase sugar-free beverages.

\section{Overall attitudes}

Attitudes have been referred to as "a person's constantly favorable or unfavorable evaluations, feelings and tendencies towards an object or idea" (Kotler \& Armstrong, 2009) and conceptualized as tendencies to evaluate an object favorably or unfavorably (Eagly \& Chaiken 1998). Attitudes also addressed by prior studies (Thurstone 1931, Ajzen \& Fishbein, 1980) as "quite coceivable that two men may have the same degree of intensity or affect favorable towards a psychological object and that their attitudes would be described in this sense as identical but that they arrived at their similar attitudes by entirely different routes." They are a distinct psychological construct, apart from the beliefs, feelings and behaviors which impact their formation, and can be stored in the memory of consumers, from where they influence new beliefs, feelings and behaviors (Thurstone 1931, Ajzen \& Fishbein, 1980). Attitudes may also be explicit, when people express them as judgments, feelings or behavior-, or implicit, when traces of past experiences are inaccurately identified (Scwartz \& Bohner 2001). Although they are silent they can influence positively or negatively consumers' thoughts, emotions and actions (Greenwald \& Banaji, 1995). Katz (1960) and Smith (1947) developed a functional theory of attitudes, suggesting that the attitudes are formed due to the functions they serve for individuals: utilitarian, value-expressive, ego-defensive and acquisition of knowledge (Albarracin, Johnson, \& Zanna, 2005). A research on attitudes by the studies of Eagly and Chaiken (1993) refer to attitudes as "tendencies to evaluate an entity with some degree of favor or disfavor, ordinarily expressed in cognitive, affective, and behavioral responses"; attitudes are formed from cognitive, affective, and behavioral processes and lead to cognitive, affective, and behavioral responses. For this study on sugar free beverages we can conclude that attitudes are learned, can be driven by feelings and emotions and can influence consumers' future behavior.

\section{Behavioral intentions}

Conation refers to individuals' behavioral intention, which is the willingness to act towards the object (Solomon 2008). Conative variable is often treated as a variable that influences to cognitive and affective components on attitudes. Intentions are "psychological constructs distinct from attitudes and the person's motivation in the sense of his or her conscious plan to exert effort to carry out a behavior" (Eagly \& Chaiken 1998). Defined by Ajzen \& Fishbein (1980) as "subjective probabilities," intentions were proposed in Theory of Reasoned Action as "immediate determinants of the action" and "likelihood that one will perform a behavior" (Fitzmaturice, 2005). 
Azjen \& Fishbein (1980) suggested that in order to determine behavioral intention, one would have to assess consumers' attitudes toward their own performance of the behavior. Intention, in this study has been applied to measure effects of cognitive and emotional constructs.

\section{METHODOLOGY}

\subsection{Data Collection}

This study measures effects of factors such as cognitive and emotional to the attitude and intention.

This study conducted surveys with about two hundred ten randomly selected subjects who have awareness and emotional feelings to the sugar-free beverages. The data collected from various ways, such as store-intercept, university students, staffs from organizations, etc.

\subsection{Operational Measures}

Multi-item scales were used to measure each of the seven constructs that served as the basis for the questionnaire items. The item scales were taken from previous studies (e.g., Bearden and Teel 1983; Ajzen and Fishbein 1980) and modified to serve the objectives of the present study. Quantitative methods, including factor analysis, regression, and ANOVA (Analysis of Variance) were applied to measure effects of cognitive, emotion, attitude, and intention toward sugar-free beverages. Likert scales, semantic differential scales, and open-ended questions were used to measure the items. For Likert scale questions, a seven-point scale was used with labels such as "Strongly Disagree" and "Strongly Agree" was used. In order to check construct reliability, this study measured Cronbach's alpha for multi-item scales to measure reliability of constructs that served as the basis for the questionnaire items. This study found that Cronbach's alpha for constructs showed over 0.80 .

\section{RESULTS}

\subsection{Respondent demographics}

172 returned the questionnaires, which results in a response rate of $82 \%$. Of the two hundred ten respondents, $62.8 \%$ were female and $37.7 \%$ were male. With regards to the level of education of those who participated in the survey, the data revealed that $43.3 \%$ respondents had graduated or were enrolled in bachelor studies and $28.0 \%$ attended master's studies or graduate schools. About $30 \%$ were between the ages $20-24 ; 41 \%$ were between the ages $25-29 ; 17 \%$ were between the ages $30-34$; and more than $10 \%$ were ages of 35 or older. One categorical question asked respondents to reflect on their main reason for consuming beverages in sugar-free drinks. Answers revealed that $46.1 \%$ of the participants to this survey chose to drink sugar-free beverages because they wanted a healthy lifestyle. Approximately $45 \%$ of participants answered that they were appealed by sugar-free drinks because of their weight control benefits.

A questionnaire item asked respondents how often they consumed sugar free beverages during the last 30 days. According to their answers, respondents can further be classified into different groups, reflecting the regularity of their behavior. Those who drink sugar-free beverages at least 3 times during one week can be regarded as regular consumers. Occasional consumers are those whose consumption was 1 to 3 times, or not at all in the last 30 days. Regular consumers may further be divided into 3 subgroups; i) heavy consumers - drinking sugar-free beverages daily or almost every day; ii) moderate consumers - consuming sugar-free beverages several times a week; and iii) light consumers - drinking once or twice a week. These subgroups may present mean differences on various variables, therefore they will be used in more advanced analyses to identify common characteristics of consumers with similar consumption patters. The analysis of frequencies indicated that about $47.7 \%$ were regarded as regular consumers, while about $9.7 \%$ of respondents responded that they had not drunk any sugar-free beverage during the past month. Respondents who declared a medium consumption of 1 to 2 drinks per week accounted for $26 \%$ of the respondents, while the remaining $16.9 \%$ were occasional consumers, using sugar-free beverages 1 to 3 times in the last 30 days. This study conducted semantic differential analysis to measure perception on sugar-free beverages. The results of means for bipolar objects on sugar-free beverages are shown in figure 2 . 


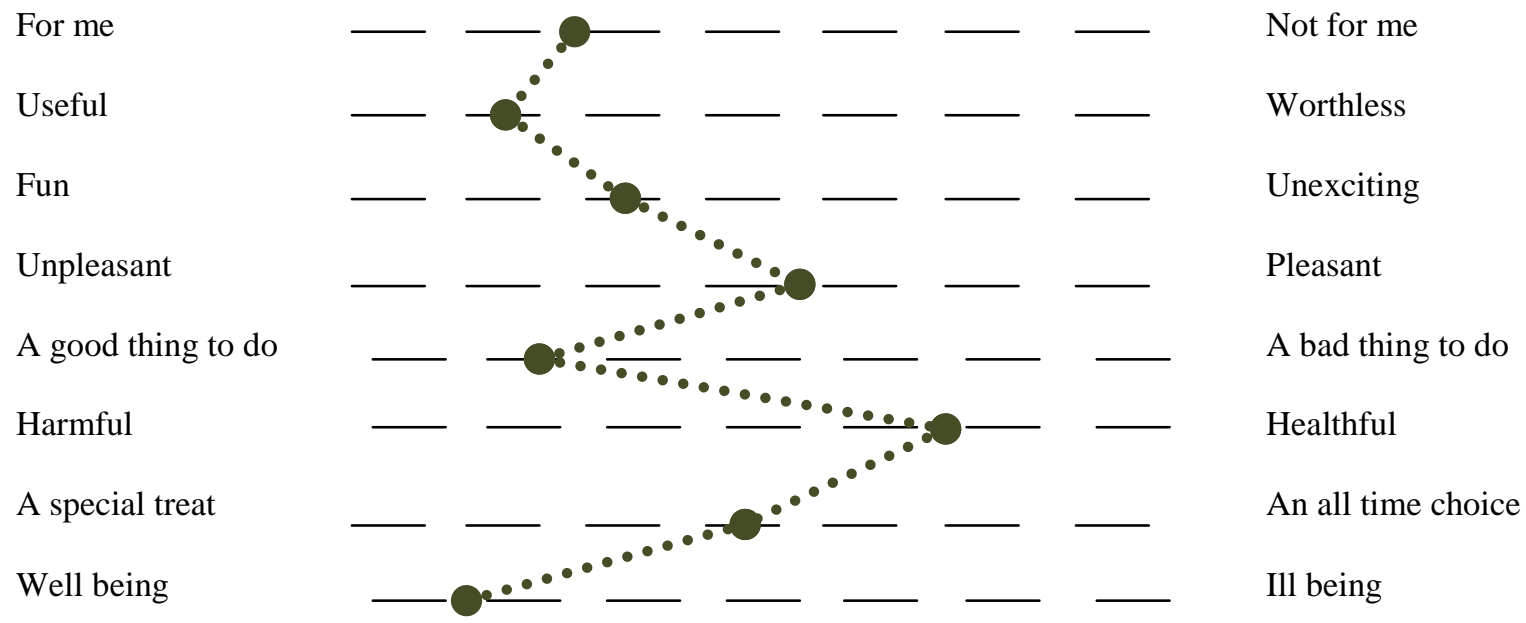

Figure 2. Semantic Differential Analysis of Perception on Sugar-free Beverages

\subsection{Hypotheses Testing}

The first step in this analysis was intended to validate the factors, such as cognitive and emotional factors. This study ran a confirmatory factor analysis to identify those factors (table 1). Using principal components analyses as the extraction method and Varimax rotation methods with Kaiser Normalization, the most relevant data emerged. These analyses showed distinct reduced factors, with Eigen values over 1.00. According to the results of factor analysis shown in table 1, components $1-4$ includes constructs of self-congruity, normative belief, perceived awareness, and emotion.

Table 1. Component Matrix

\begin{tabular}{|c|c|c|c|c|}
\hline Factors & Component 1 & Component 2 & Component 3 & Component 4 \\
\hline Sugar-free beverages match my own image of myself. & .840 & & & \\
\hline Sugar-free beverages boost my self-confidence. & .832 & & & \\
\hline I'm afraid of gaining weight if I drink regular beverages & .745 & & & \\
\hline $\begin{array}{l}\text { If I drink sugar-free beverages, I can be more attractive. } \\
\text { lantaing sugar. }\end{array}$ & .715 & & & \\
\hline $\begin{array}{l}\text { People who drink sugar-free beverages don't need to } \\
\text { worry about gaining fat. }\end{array}$ & .512 & & & \\
\hline $\begin{array}{l}\text { Most articles in magazines say that I should not drink } \\
\text { sugar-free beverages. }\end{array}$ & & 0.693 & & \\
\hline $\begin{array}{l}\text { Most people who are important to me would disapprove } \\
\text { drinking sugar-free beverages. }\end{array}$ & & 0.618 & & \\
\hline $\begin{array}{l}\text { How likely are you to be afraid of the possible harmful } \\
\text { effects of sweeteners on health? }\end{array}$ & & 0.570 & & \\
\hline $\begin{array}{l}\text { How well do you know the ingredients used to replace } \\
\text { the sugar in sugar-free beverages? }\end{array}$ & & & 0.877 & \\
\hline $\begin{array}{l}\text { How likely are you to check the ingredients or the label } \\
\text { of a drink? }\end{array}$ & & & 0.762 & \\
\hline I am eager to drink sugar-free beverages. & & & & .845 \\
\hline Sugar-free beverages are fun to drink. & & & & .765 \\
\hline $\begin{array}{l}\text { I desire to drink sugar-free beverages in the forthcoming } \\
\text { days. }\end{array}$ & & & & .755 \\
\hline $\begin{array}{l}\text { I am less more likely to enjoy drinking sugar-free } \\
\text { beverages. }\end{array}$ & & & & .723 \\
\hline
\end{tabular}


This study analyzed regression analyses and the analyses of variance (ANOVA). Factor scores were used for regression analyses. This study used regression analyses for the impacts of variables to the predictors. Table $2-$ 3 presents the results of the regression analyses for the effects of variable to the dependent variables (i.e., overall attitudes and intention) based on the Figure 1. The results in table 2 show the results of hypotheses H1- 4 were accepted at significance level of 0.01 (for $\mathrm{H} 1,2, \& 4$ ) and $0.05 \%(\mathrm{H} 3)$. The results of the analysis of variance in the case of purchase found the models significant at the .01 level with $r$-squares of .419 .

Table 2. Summary of the Effects of Variables to Overall Attitudes

\begin{tabular}{|l|c|c|}
\hline \multicolumn{1}{|c|}{ Variables } & Standardized Coefficient & $4.428(* * *)$ \\
\hline Self Congruity factor & .277 & $3.857(* * *)$ \\
\hline Normative Belief Factor & .242 & $2.583(* *)$ \\
\hline Perceived Awareness Factor & .162 & $8.102(* * *)$ \\
\hline Emotional Factor & .508 & \\
\hline
\end{tabular}

*** Significant at 0.01 level (2-tailed); ** Significant at 0.05 level (2-tailed)

The results in table 3 show the results of accepted hypotheses H1a- $4 \mathrm{a}$ at significance level of 0.01 excluding H2a. The results of the analysis of variance in the case of purchase found the models significant at the .01 level with $r$-squares of 585 .

Table 3. Summary of the Effects of Variables to Intention

\begin{tabular}{|l|c|c|}
\hline \multicolumn{1}{|c|}{ Variables } & Standardized Coefficient & $6.036(* * *)$ \\
\hline Self Congruity factor & .318 & $4.360(* * *)$ \\
\hline Perceived Awareness Factor & .230 & $12.447(* * *)$ \\
\hline Emotional Factor & .657 & \\
\hline
\end{tabular}

*** Significant at 0.01 level (2-tailed); ** Significant at 0.05 level (2-tailed)

\section{DISCUSSION AND CONCLUSION}

The model proposed for this study attempts to determine factors that can impact consumers' attitudes and intention towards sugar-free beverages, by applying theories such as the tri-component perspective on attitudes. The degree of belief regarding functional and self-concept congruity, the perceived awareness and the normative belief, and the intensity of emotions such as enjoyment, eagerness, associated with the consumption of sugar-free beverages are hypothesized to determine the levels of intention and overall attitudes. It was proposed that beliefs formed as result of past experiences are proposed to also impact the overall attitudes. The results of this study may provide implications to marketers and producers of sugar-free drinks to understand how customers perceive those products. By analyzing the data collected for this research, this study will provide direction to design and plan effective marketing strategies for reaching and better satisfying targeted segments of consumers.

This study applied and developed concepts from previously proposed theories and models related to understand consumer behavior. Furthermore, this study provides implications and offers suggestions how businesses should consider strategies by understanding customer attitudes along with messages on labels. The study has some limitations. Further research might consider the effects of classified consumer groups based on the level of perception toward sugar-free beverages. How overall attitudes and intention affect actual buying behavior, repeated behavior, and loyalty also need to be considered in the future research. This study used multivariate statistics, such as factor and regression analysis, and ANOVA, however, the study did not measure the cause and effect relationship using a program, such as LISREL. The researchers will consider this issue in future research. For future studies, researchers will also investigate causes that affect different impacts toward other products and also crosscultures/countries. For further studies, a larger number of subjects will be surveyed. 


\section{AUTHOR INFORMATION}

Ifrim Mihaela-Roxana received MBA degree from the KDI School Of Public Policy And Management. She is currently pursuing Ph.D. degree in management. Email address: mihaela_ifrim@yahoo.com

Dr. Yoon C. Cho is Associate Professor at the KDI School Of Public Policy And Management, global school, located in Seoul. She published research papers in the various academic journals such as Advances in Consumer Research (ACR), Journal of Consumer Satisfaction, Dissatisfaction, and Complaining Behavior (JCS/DCB), Hawaii International Conference on System Sciences, Journal of Business \& Economics Research, etc. yoonji22e@gmail.com

\section{REFERENCES}

1. Ajzen, I. and Fishbein, M. (1980). Understanding Attitudes and Predicting Social Behavior. Englewood Cliffs, NJ, Prentice-Hall.

2. Albarracin, Dolores, Johnson, Blair T., and Zanna, Mark P. (2005), The Handbook of Attitudes, Mahwah, NJ: Lawrence Erlbaum.

3. Bagozzi, R. P. (1978), "The Construct Validity of the Affective, Behavioral, and Cognitive Components of Attitude by Analysis of Covariance Structures," Multivariate Behavioral Research, 13, pp.9-31.

4. Bandura, A. (1977), "Self-Efficacy: Toward a Unifying Theory of Behavioral Change," Psychological Review, 84, pp.191-215.

5. Bandura, A. (1982), "Self-Efficacy Mechanism in Human Agency," American Psychologist, 37, pp.122-47.

6. Bearden, William O. and Jesse E. Teel (1983), "Selected Determinants of Consumer Satisfaction and Complaint Reports," Journal of Marketing Research, 20, February, 21-8.

7. Bettman, James R., Payne, John W., and Staelin, Richard (1986), "Cognitive Considerations in Designing Effective Labels for Presenting Risk Information," Journal of Public Policy and Marketing. Vol.5, pp.1-28.

8. Blackwell, Roger D., Miniard, Paul W., and Engel, James F. (2006), Consumer Behavior, $10^{\text {th }}$ edition, Thomson South Western.

9. Brown, Vernon, Kelly, Craig, A. and Lee, Ming-Tung (1991), "The-State-of-the-Art in Labeling Research Revisited: Developments in Labeling Research, 1978-1990," paper presented to the 1991 Summer Educators' Conference of the American Marketing Association.

10. Bucklin, Louis P. (1963), "Retail Strategy and the Classification of Consumer Goods," Journal of Marketing, Vol.27 (1), pp. 50-55.

11. Eagly, A. H. \& Chaiken, S (1998), Attitude Structure and Function, in D. T. Gilbert and S. T. Fiske (eds), The Handbook of Social Psychology, $4^{\text {th }}$ ed., Vol.1, pp.269-322, Boston, MA: McGraw-Hill.

12. Earl P. E.\& Kemp, S. (1999), The Elgar Companion to Consumer Research and Economic Psychology, Edward Elgar Publishing Limites, UK

13. Easterling, D. V. and Leventhal, H. (1989), "Contribution of Concrete Cognition to Emotion: Neutral Symptoms as Elicitors of Worry about Cancer," Journal of Applied Psychology, 74, pp.787-796.

14. Glanz, R. K., \& Lewis, B. K. (2002). Health Behavior and Health Education. Theory, Research and Practice. San Fransisco: Wiley \& Sons

15. Fitzmaurice, J. (2005). Incorporating Consumers' Motivations into the Theory of Reasoned Action. Psychology \& Marketing, pp. 911-929.

16. Freud, S. (1953). Life and Work. Hogarth Press.

17. Greenwald, Anthony G, and Banaji, Mahzarin R. (1995), "Implicit Social Cognition: Attitudes, SelfEsteem, and Stereotypes," Psychological Review, Vol.102, Issue 1, pp. 4-27.

18. Grubb, E.L. \& Grathwohl H. L., (1967), Consumer self-concept, symbolism and market behavior. A theoretical approach, Journal of Marketing (31), 22-27.

19. Gutman, Jonathan (1982), "A Means-End Chain Model Based on Consumer Categorization Processes," Journal of Marketing, Vol. 46, pp. 60-72.

20. Hilton, Michael E. (1993), “An Overview of Recent Findings on Alcoholic Beverages Warning

21. Labels," Journal of Public Policy and Marketing, 12, 1, pp. 1-9.

22. Johar, J.S and Sirgy, M. Joseph (1991), "Value-Expressive Versus Utilitarian Advertising Appeals: When And Why To Use Which Appeal," Journal of Advertising Vol.20 (3), pp22-33. 
23. Johnson, E. J. and Payne, J. W. (1985), "Effort and Accuracy in Choice,” Management Science, 31, pp.394 $-414$.

24. Kahle, L. R. (1983). Attitudes and Social Adaptation: A Person-Situation Interaction Approach. London: Pergamon.

25. Katz, D. (1960), "The Functional Approach to the Study of Attitudes," Public Opinion Quarterly, 24, pp. 163-204.

26. Kotler, P., \& Armstrong, G. (2009), Principles of Marketing, 13th ed., Pearson Prentice Hall.

27. Krugman, H. E, and Hartley, E. L.(1970), "Passive Learning from Television," Public Opinion Quarterly, 34, pp.184-190.

28. Lang, P. J. (1984), Cognition in Emotion: Concept and Action, in C. F. Izard, J. Kagan, \& R. B. Zajonk Eds., Emotions, Cognition, and Behavior, pp. 192-226, Cambridge: Cambridge University Press.

29. Little, D. C. John, S (2002), Theories of Human Communication, California: Wadsworth Thomson Learning.

30. Maslow, Abraham (1954), Motivation and Personality, NY: Harper.

31. Mayer, Robert N., Smith, Ken R., and Scammon, Debra L. (1991), "Evaluating the Impact of Alcohol Warning Lables," Advances in Consumer Research, Vol. 18, pp.706-714.

32. Mazis, Michael B., Staelin, Richard, Beales, Howard, and Salop, Steven (1981), “A Framework for Evaluating Consumer Information Regulation,” Journal of Marketing, 45, Winter, pp.11-21.

33. Meyer, C., (2008), "Uniqueness of Korean Cuisine (IV) - Tea," The Korea Times.

34. Miller, John (1978), Labeling: State of the Art, Cambridge, MA: Marketing Science Institute.

35. Muller, Thomas, E. (1985), "Structural Information Factors Which Stimulate the Use of Nutrition Information: A Field Experiment," Journal of Marketing Research, Vol.22, pp. 143-57.

36. Orthony, A. and Turner, T. J. (1990), "What's Basic about Basic Emotions?" Psychological Review, 97 , pp.315-331.

37. Payne, John W., Bettman, James R., Johnson, Eric J. (1993), The Adaptive Decision Maker, Cambridge University Press.

38. Rogers, R. W. (1975), "A Protection Motivation Theory of Fear Appeals and Attitude Change," Journal of Psychology, Vol. 91, Issue 1, pp. 93-114.

39. Rosenberg, Milton J. (1956), "Cognitive structure and attitudinal affect," Journal of Abnormal and Social Psychology, Vol.53 (3), pp. 367-372.

40. Rosenberg, M. J. and Hovland, C. I. (1960), Cognitive, Affective, and Behavioral Components of Attitudes, in C. I. Hovland and M. J. Rosenberg (eds), Attitude Organization and Change: An Analysis of Consistency among Attitude Components, pp.1-14, New Haven, CT: Yale University Press.

41. Rotter, J. B. (1954), Social Learning and Clinical Psychology, Oxford: Prentice-Hall.

42. Schiffman, Leon G. and Kanuk, Leslie L. (2003), Consumer Behavior, $8^{\text {th }}$ edition, Prentice Hall.

43. Scwartz, N. and Bohner, G. (2001), The Construction of Attitudes, in A. Tesser \& N. Schwarz (eds.), Blackwell Handbook of Social Psychology: Intraindividual processes, pp. 436 - 457, Malden, MA: Blackwell Publishers.

44. Sirgy, M. Joseph (1986), Self-congruity: Toward a Theory of Personality and Cybermetics, Praeger, New York, NY.

45. Smith, M. B. (1947), "The Personal Setting of Public Opinions: A Study of Attitudes toward Russia," Public Opinion Quarterly, 11, pp. 507-523.

46. Solomon, Michael (2008), “Consumer Behavior: Buying, Having, and Being," $8^{\text {th }}$ edition, Pearson Prentice Hall.

47. Thurstone, L., L. (1931), "The measurement of social attitudes," Journal of Abnormal and Social Psychology.

48. Wright, Newell, D., Clairbone, C. B., and Sirgy, M. Joseph (1992), "The Effects of Product Symbolism on Consumer Self-Concept," Advances in Consumer Research, Vol. 19, pp. 311-318.

49. Stewart, David W. and Martin, Ingrid M. (1994), "Intended and Unintended Consequences of Warning Messages: A Review and Synthesis of Empirical Research," Journal of Public Policy and Marketing, Spring, Vol. 13 (1), pp.1-19.

50. Torres, Ivonne M., Sierra, Jeremy J., and Heiser, Robert S. (2007), "The Effects of Warning-Label Placement in print Ads," Journal of Advertising, Vol.36, Issue 2, pp. 49-62. 
51. Torres, Ivonne M., Gelb, Betsy, D., and Noriega, Jaime, L. (2003), "Warning and Informing the Domestic International Market," Journal of Public Policy and Marketing, Vol.22, Issue 2, pp. 216-222.

52. Witte, K. (1998), Fear as Motivator, Fear as Inhibitor: Using the Extended Parallel Process Model to Explain Fear Appeal Successes and Failures, pp. 423-450, in P. A. Andersen and L. K. Guerrero (Eds.), The Handbook of Communication and Emotion: Research, Theory, Applications, and Contexts. San Diego, CA: Academic Press.

53. Witte K. (1992), "Putting the Fear Back into Fear Appeals: The Extended Parallel Model," Communication Monographs, Vol. 59 (4), pp. 329-349. 